\title{
Cyrtosathe gen. n.: the first non-scenopinine window fly from sub- Saharan Africa (Diptera: Scenopinidae)
}

\author{
SHAUN L. WINTERTON ${ }^{1} \&$ MARK A. METZ ${ }^{2}$ \\ 1. Address: Plant Pest Diagnostics Branch, California Department of Food and Agriculture, Meadowview \\ Road, Sacramento, California, 95832,USA. Email: swinterton@cdfa.ca.gov \\ 2.Address: Research Affiliate, Center for Biodiversity, Illinois Natural History Survey, Champaign, Illinois, \\ 61820,USA.Email:mametz@aol.com
}

\begin{abstract}
An unusual new genus of Scenopinidae is described and figured from Namibia. Cyrtosathe kirkspriggsi gen. et sp. nov., represents the first record of a non-scenopinine window fly from subSaharan Africa. This monotypic genus does not fit well into the current classification of Scenopinidae and is likely an intermediate form between the subfamilies Proratinae and Scenopininae. The phylogenetic position of Cyrtosathe kirkspriggsi gen. et sp. nov. is discussed with respect to previous studies on Scenopinidae relationships and classification.
\end{abstract}

Key words: systematics, Asiloidea, Brachycera

\section{Introduction}

Scenopinidae are a cosmopolitan group of lower brachyceran flies. Adults are typically small and dark with a body size rarely greater than $5.0 \mathrm{~mm}$. Although found in a variety of habitats, by far the greatest diversity of this group is in arid regions where sandy soils provide a suitable habitat for the larvae. As larvae, scenopinids are elongate, fossorial predators of arthropods in friable soils and leaf litter, although larvae have also been reared from, or suspected of breeding in, a variety of habitats including galleries of wood-boring beetles, birds nests, mammal nest holes, bat caves, beehives and stored products (Kelsey 1969, Rahman et al. 1981, Yucel 1988, Gnaspini 1989, Yao \& Lo 1992, Dobson 1999). A single case of human urogenital myasis is recorded for a larva of Scenopinus Latreille (Thompson et al. 1970), but this case appears to be exceptional. Some adult scenopinids apparently do not to feed (e.g. Belosta Hardy), but many are nectar and honeydew feeders and are often collected by sweeping flowers and foliage (Kelsey 1975, 1987). Adults of 
some species (e.g. Scenopinus spp.) are often collected on windows inside human dwellings due to their predation as larvae on pests associated with human activities; hence leading to their common name as window flies (Kelsey 1969, 1981).

Scenopinidae are placed in the superfamily Asiloidea, and are widely accepted as the sister-group to the stiletto flies (Therevidae) based on secondary segmentation of the larval abdomen (Woodley 1989, Yeates 2002). Scenopinidae are strongly supported as a monophyletic clade based on several synapomorphic characters, but Therevidae are defined only by plesiomorphic characters (Woodley 1989, Yeates 1992). Consequently, Therevidae have not been unequivocally shown to be monophyletic with respect to Scenopinidae, with the latter possibly being a nested lineage within therevids (Woodley 1989, Yeates 1992). Moreover, the relatively recent erection of two closely related families, Apsilocephalidae (Nagatomi et al. 1991) and Ocoidae (Yeates et al. 2003) renders the relationships among this 'therevoid' clade (i.e. Therevidae+ Scenopinidae+ Ocoidae+ Apsilocephalidae) as undefined, awaiting further study. To support the erection of Ocoidae, Yeates et al. (2003) presented a limited phylogeny of the 'therevoid' clade based on 28S ribosomal DNA indicating a relationship of Apsilocephalidae+ (Ocoidae+ (Therevidae+ Scenopinidae)). In this study the sister-group relationship of (Scenopinidae+ Therevidae) is relatively well supported, but there is relatively weak, or almost equivocal, support for the sister-group relationship for Ocoidae+ (Therevidae+ Scenopinidae). The phylogenetic relationships among members of this clade are still unclear and require further study at all taxonomic levels.

Worldwide, more than 420 currently valid species of Scenopinidae in 24 genera have been described. The family is divided into three subfamilies, Scenopininae, Caenotinae and Proratinae. Ninety-five percent of scenopinid species are placed in Scenopininae, with the rest divided unevenly between the Caenotinae and Proratinae. Scenopininae (historically Scenopinidae sensu stricto) and Proratinae are considered as sister-groups, with Caenotinae sister to this clade (Yeates 1992). Caenotinae is comprised of a single genus, Caenotus Cole, with five species from the southwestern United States and Mexico (Cole 1923, Melander 1950, Nagatomi et al. 1994, Metz 2003). The subfamily Proratinae comprises five genera: Prorates Melander, Caenotoides Hall and Acaenotus Nagatomi \& Yanagida from North America; Jackhallia Nagatomi \& Liu from Argentina; and Alloxytropus Bezzi from the Palaearctic region (Melander 1906, Bezzi 1925, Hall 1972, Nagatomi et al. 1994). The most derived group are Scenopinine. This group of window flies is cosmopolitan in distribution, but there is significant continental endemism at the genus level with very few genera found in more than one biogeographical region.

The classification and phylogenetic placement of the non-scenopinine window flies has historically been highly labile. Caenotus was originally described in Therevidae by Cole (1923), while Prorates was originally described by Melander (1906) in Empididae. Melander (1928) later placed both genera in the subfamily Heterotropinae (Bombyliidae), to which Hall (1972) subsequently added Caenotoides, noting also that the subfamily com- 
prised an anomalous group of small bee flies. Alloxytropus has been considered a synonym of Prorates by some authors (Melander 1950, Hall, 1972, Hull 1973, Bowden 1980), but distinct by others (Evenhuis 1991, Nagatomi et al. 1994). Evenhuis (1991) later moved all the genera but Heterotropus Loew from Heterotropinae to the subfamily Proratinae, along with the enigmatic Apystomyia Melander. Finally, Yeates (1992) moved Caenotus, Alloxytropus, Caenotoides and Prorates to the family Scenopinidae, placing Caenotus in the subfamily Caenotinae and the later three genera in the subfamily Proratinae. Following Yeates (1992) but considering Caenotus in Proratinae, Nagatomi et al. (1994) described two additional genera, Acaenotus and Jackhallia.

All but one genus of Caenotinae and Proratinae are found exclusively in the New World. The single Old World genus, Alloxytropus, is distributed throughout the Palaearctic from Mongolia to Egypt (Bezzi 1925, Zaitzev 1972a,b). In this present article, we describe the first non-scenopinine scenopinid from southern Africa. The new monotypic genus $C y r-$ tosathe gen. nov., is described and figured from specimens collected in the Luderitz District of Namibia. All specimens were collected from Malaise and pitfall traps. Both males and females of Cyrtosathe gen. nov. are highly distinctive, 'proratine'-like scenopinids based on genitalic and external characteristics, but this new genus exhibits characteristics of all three scenopinid subfamilies; consequently it cannot be placed in any of the subfamilies as they are presently defined. The apparent contradictory phylogenetic data and uncertain subfamilial placement of Cyrtosathe gen. nov. are discussed in detail.

\section{Materials and Methods}

Terminology for wing venation follows Yeates (1992) and that for vestiture and genitalic morphology (including external genitalia and subterminal segments) follows Winterton et al. $(1999 \mathrm{a}, \mathrm{b})$. Whole specimens and genitalia were macerated in $10 \% \mathrm{KOH}$ at room temperature for one day to remove soft tissue, then rinsed in distilled water and dilute acetic acid, and dissected in $80 \%$ ethanol. Female reproductive organs were stained with a saturated solution of Chlorazol Black in $40 \%$ ethanol. Preparations were then placed into glycerine and glycerine gel, with figures drawn with the aid of a camera lucida mounted on a compound microscope. Genitalia preparations were placed in glycerine in a genitalia vial mounted on the pin beneath the specimen. Specimens examined were given a unique "MEI" number (label on specimen pin). These numbers are quoted in parentheses in the material examined list for future reference for specimen data-base entry, identification and location. MEI numbers have been entered into a web-based specimen database ('MANDALA') (http://pherocera.inhs.uiuc.edu/index.htm) held at the Illinois Natural History Survey, Champaign. Types are deposited in the National Museum of Namibia, Windhoek, Namibia (NMNW), the United States National Museum, Smithsonian Institution, Washington D.C., USA (USNM) and the M.E. Irwin collection (MEIC) for future deposition with the California Academy of Sciences, San Francisco, CA, USA (CASC). To avoid rep- 
etition, the following description combines both genus and species descriptions since, as it is a monotypic genus, the two cannot be separated.

\section{Taxonomy}

\section{Cyrtosathe kirkspriggsi Winterton \& Metz gen. et sp. nov.}

(Figs 1-4)

Type species. Cyrtosathe kirkspriggsi sp. nov. by present designation.

Etymology. Cyrtosathe is derived from the Greek, cyrto, bent; sathe penis. The specific epithet is named in honour of Ashley Kirk-Spriggs, the collector of the type series.

Type material: Holotype male, NAMIBIA: Luderitz District, Ob[i]b Waters, pitfall trap (2800’08”S, 16³6’46”), 10-26.viii.1998, Kirk-Spriggs \& Marais (MEI\#119440) (NMNW). Paratypes, NAMIBIA: 2 males, 1 female, same data as holotype (MEI\#119434, 119442, 119465) (USNM); male, Obib Waters, Malaise trap (2800’08”S, 16³8'46”) 2526.viii.1998, Kirk-Spriggs \& Marais (MEI\#112932) (USNM); 6 males, 1 female, Luderitz District, 8 km W Rosh Pinah, pitfall trap (2759'28”S, 16³9í14”) 20-26.viii.1998, KirkSpriggs \& Marais (MEI\#119436, 119438, 119441, 119445-6, 119451, 119453) (NMNW); 1 male, 1 female, Luderitz District, 8 km W Rosh Pinah, Malaise trap (2759'28”S, 16³9’14”) 20-26.viii.1998, Kirk-Spriggs \& Marais (MEI\#119448, 119454) (MEIC/ CASC).

Diagnosis. Autapomorphic characters: Female tergite 8 covered with erect, elongate setae arranged in a ring pattern (i.e. glabrous centre); hypandrium bowl-like with posterior processes; dorsal apodeme of parameral sheath enlarged into a 'ladle'-like structure enclosing ejaculatory apodeme; aedeagus folded onto itself posteriorly such that the ejaculatory apodeme is directed posteriorly. Shared characters with other genera: head and thorax mostly glabrous; costal vein ending just past $\mathrm{R}_{5}$; wing vein $\mathrm{M}_{2}$ present; hind coxal knob absent; abdominal tergite 2 sensory patch present as two hemispheres, sensory setae with apices acute (not truncated); male epandrium divided medially; hypandrium separate from gonocoxites; gonocoxal apodeme slightly longer than gonocoxites; distiphallus bifid, greatly elongate and narrow; ventral apodeme of parameral sheath absent.

Description. Body length: 2.0-2.5 mm. Head. Spherical, glossy dark brown to black; frons glabrous, narrow in male (Figs 1A, B) with eyes contiguous along middle third, female (Figs 1C, D) frons much wider than ocellar tubercle along entire length; male eyes with facets larger in upper half; ocellar tubercle raised, ocelli red-brown; occiput flat to slightly concave laterally; postocular ridge with irregular rows of minute postocular setae; gena with short setae; mouthparts brown, relatively elongate, approximately equal in length to antennae; labellum relatively small and rounded; antenna (Fig. 1E) brown, overlain with fine silver pruinescence; scape and pedicel short, broad; flagellum $2 x$ length of pedicel, flattened, apex pointed; style apical, single segment. 
Thorax. Glossy black, glabrous except for fine, pale setae on katepisternum and short

dark setae on proepimeron and scutellum; macrosetae absent; wing (Fig. 2) hyaline, venation pale, venation in posterior half of wing poorly sclerotised and difficult to detect; costal vein ending at $R_{5}$ vein; vein $M_{2}$ present, extending from middle of discal cell; haltere stem brown, knob pale cream-white; legs dark brown to black, tibiae pale yellow, covered with fine pale setae.
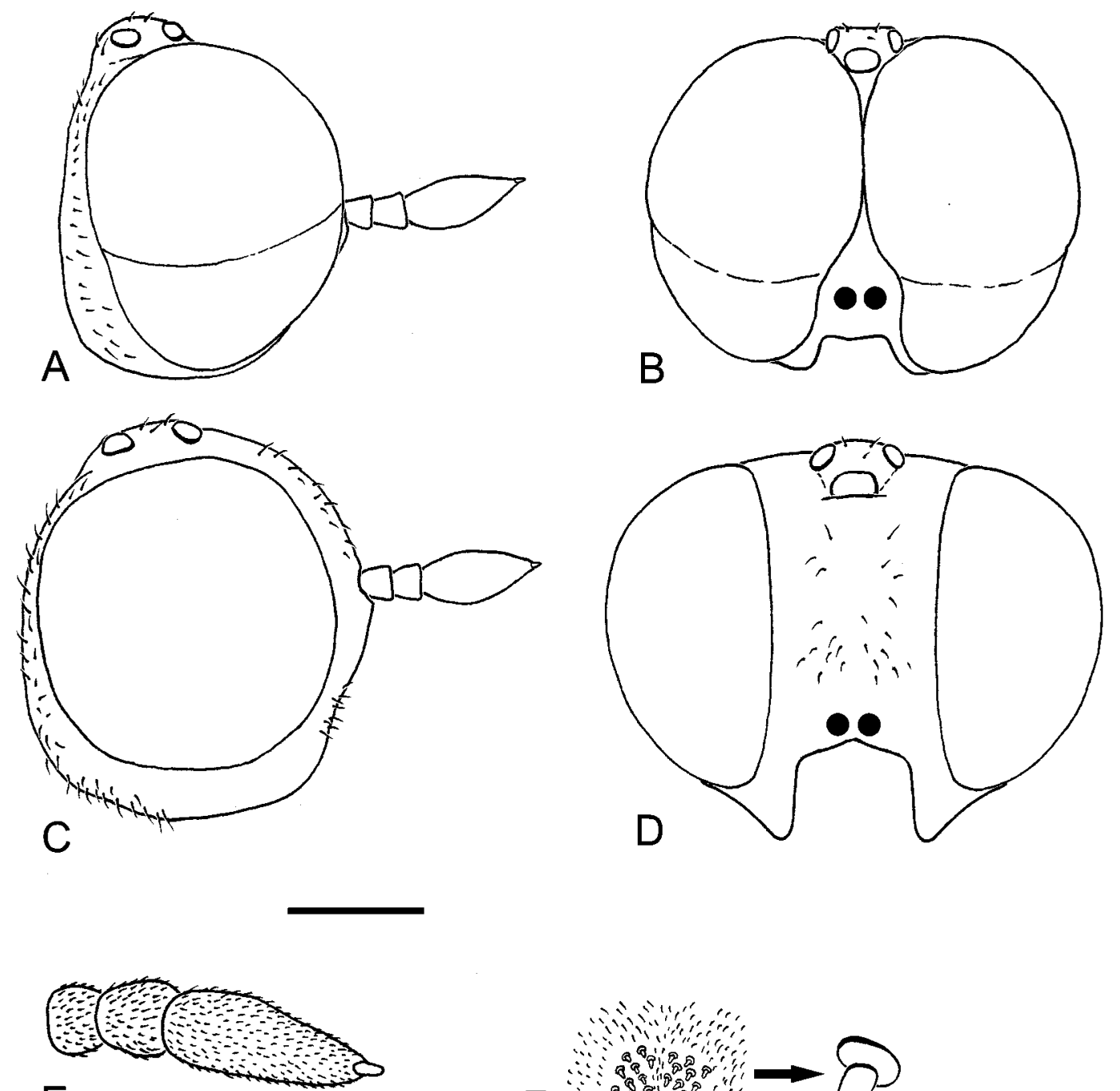

$E$

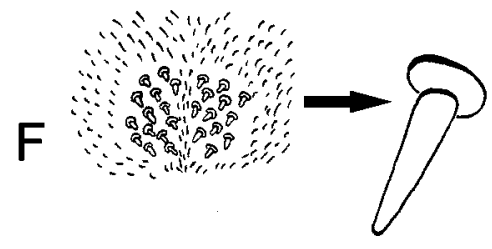

FIGURE 1. Cyrtosathe kirkspriggsi gen. et sp. nov.: Male: A, head, lateral; B, same anterior. Female: C, head lateral; D, same anterior; E, antenna, right lateral. F, abdominal tergite 2 sensory setae patch (enlarged at right). Scale lines: $0.1 \mathrm{~mm}$. 


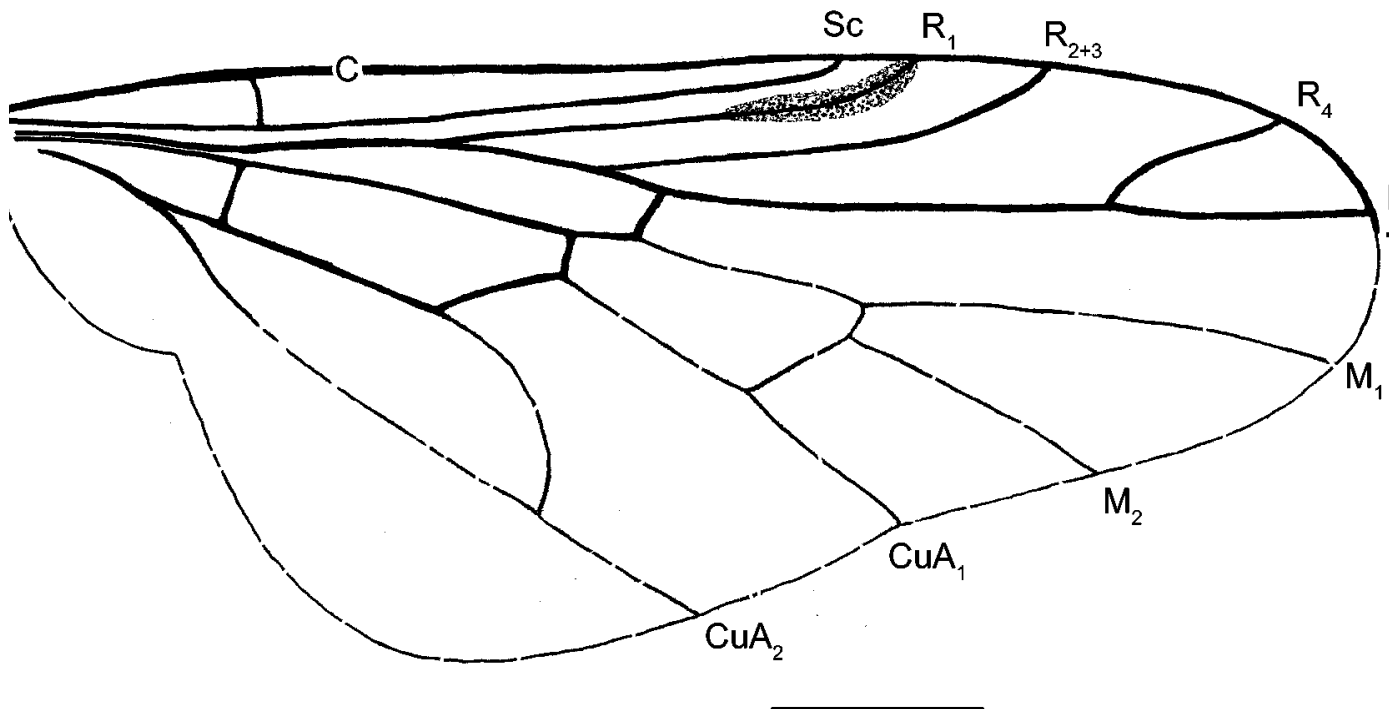

FIGURE 2. Cyrtosathe kirkspriggsi gen. et sp. nov.: Wing. Scale line: $0.2 \mathrm{~mm}$.

Abdomen. Glossy black, sparsely covered with elongate, pale setae in male; tergite 2 with two medial hemispherical patches of sensory setae (Fig. 1F).

Male Genitalia. Genitalia aligned with body axis (i.e. epandrium dorsal), not rotated; epandrium (Figs 3A, C) quadrangular, arched, covering terminalia, split medially in two sections; cerci short, rounded; gonocoxites (Figs 3B-C, E-F) elongate with spatulate posterior process and a short, strong seta dorsally; gonocoxites widely separated medially by a large rounded bowl-like hypandrium; hypandrium with paired posterior processes and medial process (Figs 3B-C, E-F); gonostylus elongate, narrow, apical third upturned slightly; gonocoxal apodeme elongate, equal to gonocoxite in length, curved outwards then recurved inwards at apex around dorsal apodeme of parameral sheath, apex spatulate; aedeagus extended anteriorly beyond gonocoxites, folded dorsally on itself, distiphallus bifid, greatly narrowed, elongate, slightly coiled, ribbon-like lateral flanges near base; dorsal apodeme of parameral sheath large, 'ladle'-shaped with lateral wings at base, cradling ejaculatory apodeme (Figs 3B-E); lateral ejaculatory apodemes not clearly evident; ejaculatory apodeme narrow with greatly enlarged paddle-shaped apex posteriorly.

Female Genitalia. Tergite 8 covered with erect, elongate pale setae arranged in a ringlike pattern (i.e. glabrous in the centre) (Fig. 4A); tergite 9+10 joined to furca internally by a bridge formed by tergite 9 (Figs 4B-C); acanthophorites with four to six stout A1 setae; furca (Fig. 4C) circular, lightly sclerotised; sternite 8 bowl shaped; two spermathecae present; spermathecal ducts thickened basally, narrower distally, with reticulated tissue patterning; spermatheca membranous, truncated distally with thickened marginal band; spermathecal sac very small; spermathecae join to roof of bursa separately from and 
immediately posterior of spermathecal sac duct; accessory glands join to bursa just posterior to spermathecae.

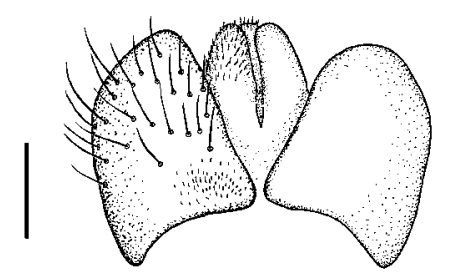

A
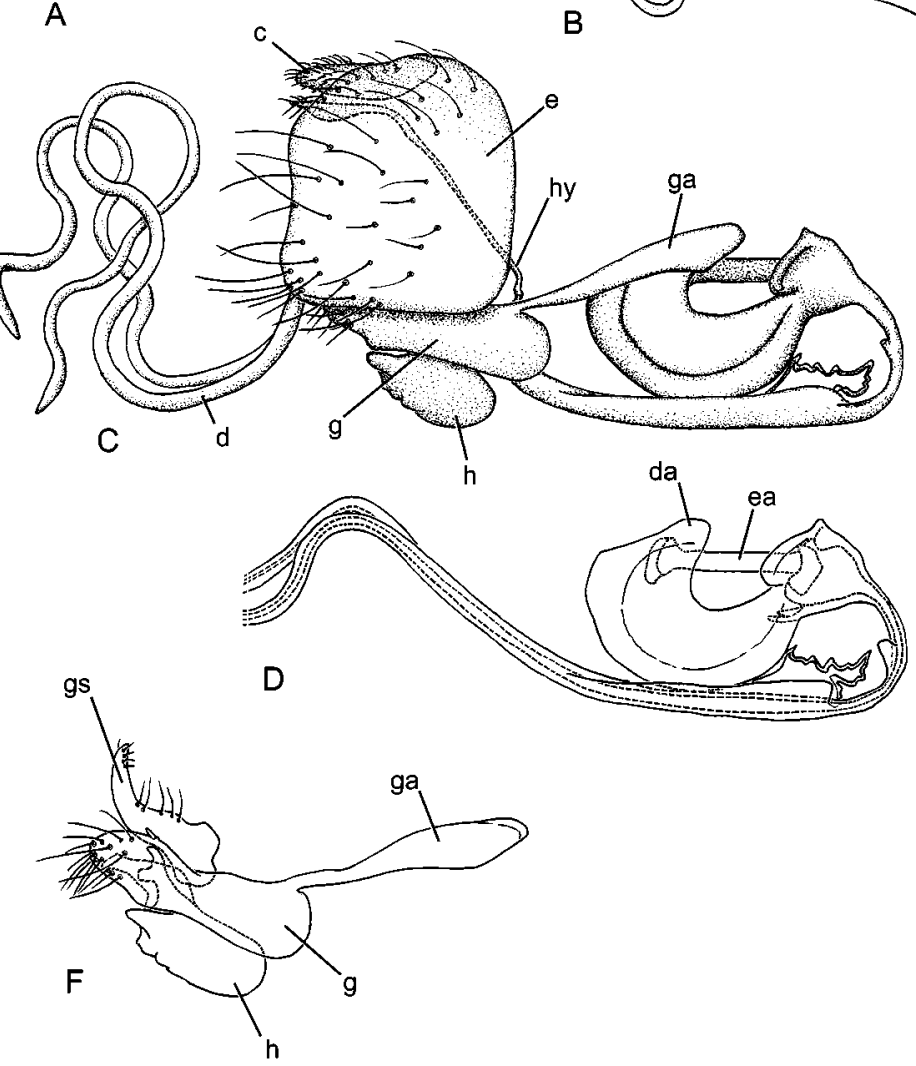
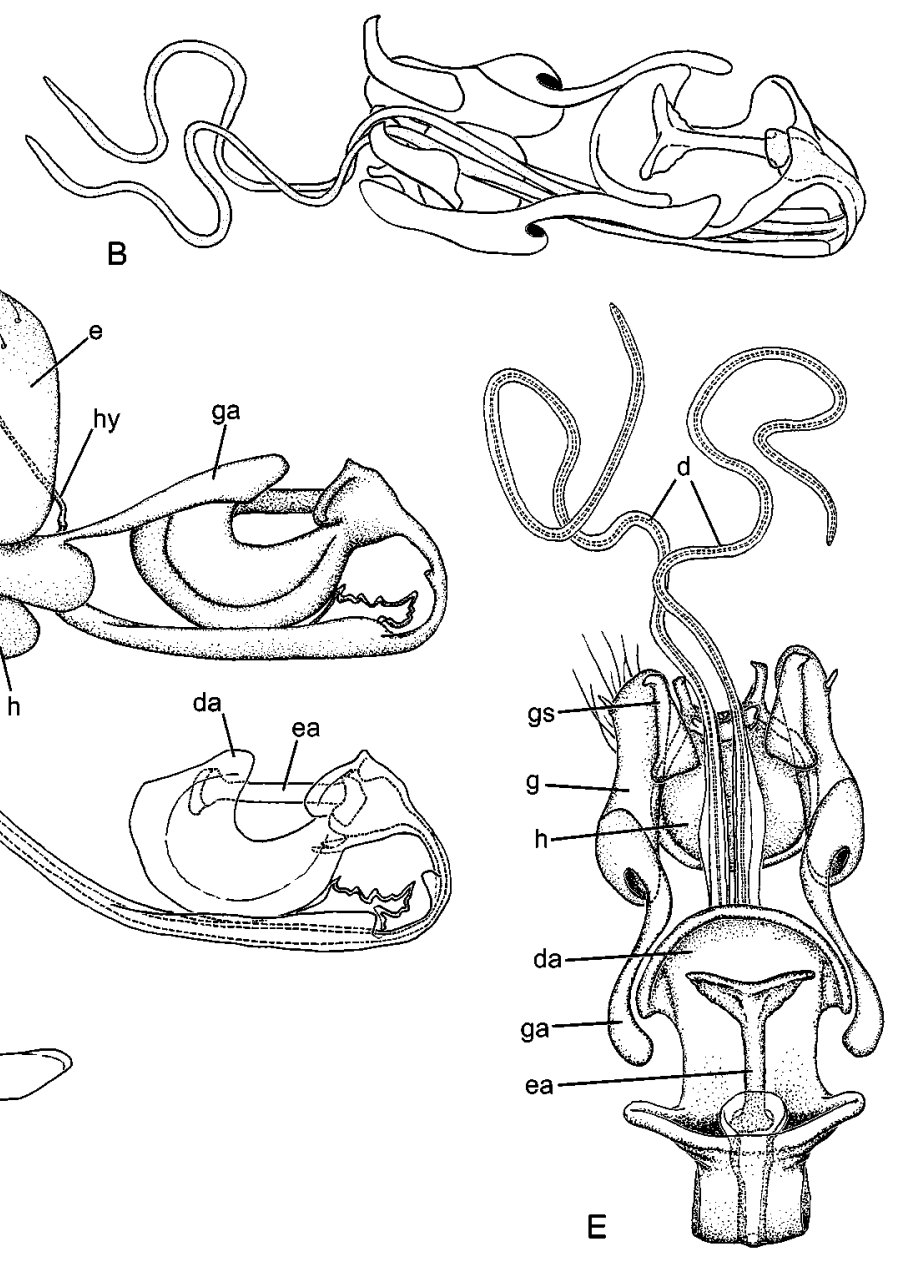

FIGURE 3. Cyrtosathe kirkspriggsi gen. et sp. nov.: Male genitalia: A. Epandrium, dorsal; B, aedeagus and gonocoxites (epandrium and vestiture removed), dorso-lateral view; C, same, lateral; $\mathrm{D}$, detail of basal portion of aedeagus, lateral; E, aedeagus and gonocoxites, dorsal; $\mathrm{F}$, detail of gonocoxites. lateral, Scale line: $0.1 \mathrm{~mm}$. Abbreviations: $c$, cercus; $d$, distiphallus; $d a$, dorsal apodeme of parameral sheath; $e$, epandrium; $e a$, ejaculatory apodeme; $g$, gonocoxite; $g a$, gonocoxal apodeme; $g s$, gonostylus; $h$, hypandrium; hy, hypoproct.

Comments. Cyrtosathe kirkspriggsi gen. et sp. nov. is known from a single collecting locality in the Luderitz District, Namibia. All adults were collected by Malaise and pitfall traps. As with all other non-scenopinine window flies, the immature stages are unknown. The type series is only in fair condition as most specimens are shriveled, presumably when they were removed from alcohol and mounted. 

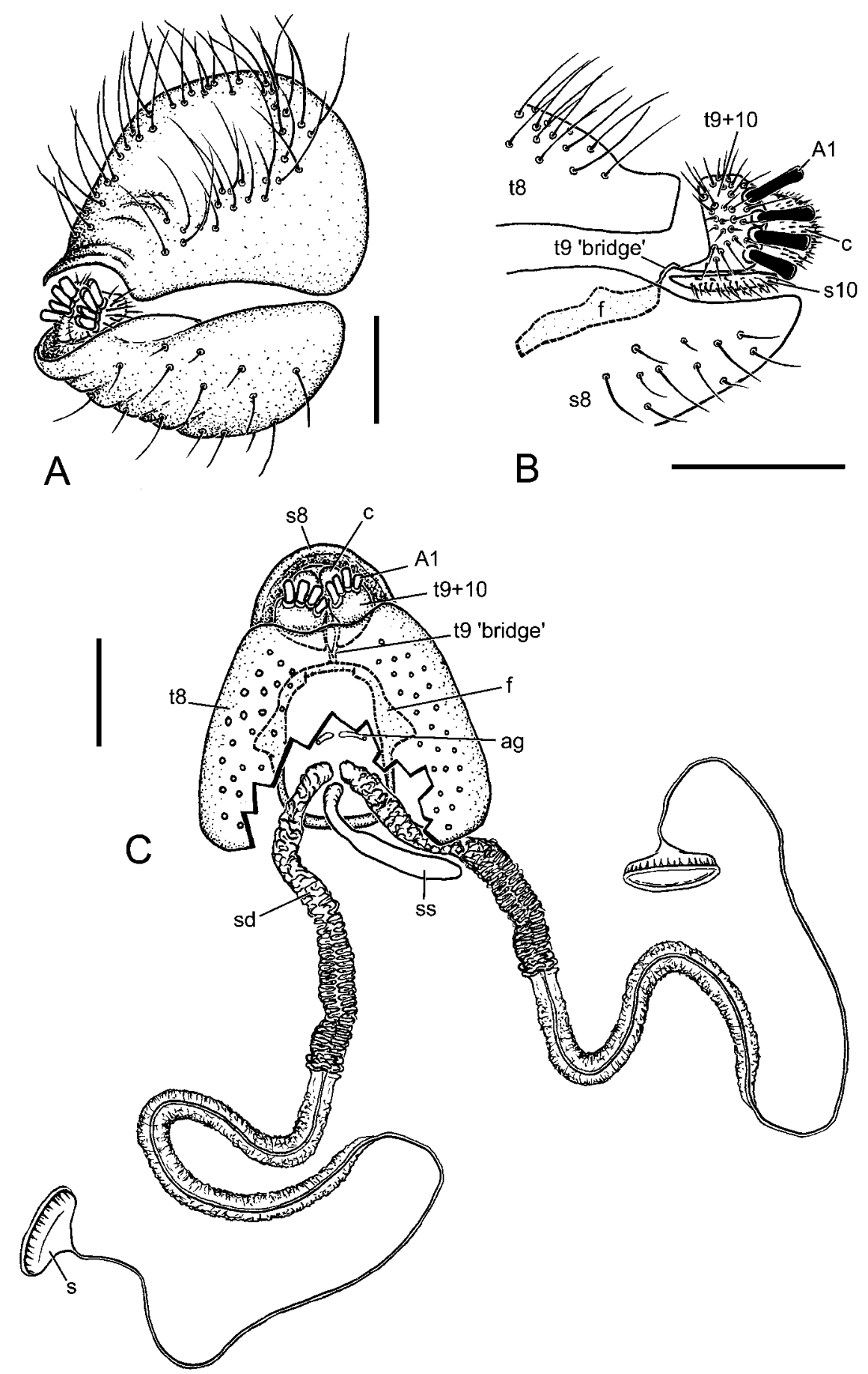

FIGURE 4. Cyrtosathe kirkspriggsi gen. et sp. nov.: Female genitalia: A, Genitalia in contacted position, postero-lateral; B, detail of same with acanthophorites slightly relaxed posteriorly, lateral; $\mathrm{C}$, same, showing distal reproductive system (tergite 8 cut away and vestiture removed), dorsal. Scale lines: $0.1 \mathrm{~mm}$. Abbreviations: $A 1$, acanthophorite macrosetae; $a g$, accessory gland duct (gland cut away); $f$, furca; $s s$, spermathecal sac; $s$, spermatheca; $s d$, spermathecal duct; $s \delta$, sternite 8 ; 10 , sternite $10 ; t 8$ - $t 10$, tergites 8 to 10 . 
Cyrtosathe gen. nov. is clearly placed in Scenopinidae based on the presence of several synapomorphies found in members of Scenopinidae, including: (1) abdominal tergite 2 with a patch of sensory setae present medially, (2) epandrium divided along midline into two sclerites and (3) bifid distiphallus. The abdominal tergite 2 patch of sensory setae is characteristic of all Scenopinidae except Caenotoides and is considered a strong synapomorphic character for the family (Yeates 1992). Winterton et al. (1999a, 2000, 2001) described similarly shaped, though less ornate, patches of sensory setae on tergite 2 in several genera of Australian Therevidae (e.g. Nanexila Winterton \& Irwin, Neodialineura Mann, Bonjeania Irwin \& Lyneborg, Pipinnipons Winterton), although this structure appears to be independently derived. The split epandrium is found in all Scenopinidae except Caenotus hospes Melander (see Nagatomi et al. 1994). The same character is also found in Ocoidae, Apioceridae, Mydidae and some Asilidae, but Cyrtosathe gen. nov. does not share any other apomorphic characters that would support inclusion in any family other than Scenopinidae. Similarly, a bifid or trifid aedeagus is also present in other asiloid families such as Asilidae and Bombyliidae, but not in the often greatly elongate and highly coiled form found in some Scenopinidae. The phylogenetic position of Cyrtosathe gen. nov. in Scenopinidae is problematic based on the present subfamilial classification (sensu Yeates 1992) as Cyrtosathe gen. nov. has characteristics from all three subfamilies (see Table 1). Cyrtosathe gen. nov. has a well-defined hypandrium, similar to that of Caenotus, but lacks other characters to suggest a close relationship. Abdominal tergite 2 sensory setae in the shape of two hemispherical patches are found in both Scenopininae and Cyrtosathe gen. nov., although also found in some individuals of Caenotus tanyrhynchus Metz (Metz 2003). Cyrtosathe gen. nov. has proratine characters such as elongate gonocoxal apodemes, wing costal vein ending at wing apex and a single patch of tergite 2 sensory setae, but lacks scutal macrosetae and has a hypandrium. The presence of a spermathecal sac appears to be plesiomorphic for the 'therevoid' clade, as it is present in Apsilocephalidae, Ocoidae, most Therevidae and Scenopinidae (Winterton et al. 1999a, b, Metz et al. 2002, Yeates et al. 2003). Records of a spermathecal sac being present in Apioceridae, Asilidae and Mydidae (Irwin \& Wiegmann 2001, Metz et al. 2002) appear to be misinterpretations of a modified third spermatheca rather than an actual spermathecal sac (unpublished data).

The combination of characters exhibited by Cyrtosathe gen. nov. suggest an intermediate position between Proratinae and Scenopininae, although there are some overall morphological similarities with Prorates indicating a possible inclusion in Proratinae. At this stage Cyrtosathe gen. nov. can at best be placed conservatively as incertae sedis in Scenopinidae as it lacks diagnostic characters to place it in any of the subfamilies as they are presently defined. 
TABLE 1. Distributions of some diagnostic characters for subfamilies of Scenopinidae and Cyrtosathe gen. nov.

\begin{tabular}{|c|c|c|c|c|}
\hline & $\begin{array}{l}\text { Cyrtosathe } \\
\text { gen. nov. }\end{array}$ & Caenotinae & Proratinae & Scenopininae \\
\hline Wing costal vein & $\begin{array}{l}\text { ending at wing } \\
\text { apex }\end{array}$ & $\begin{array}{l}\text { extending } \\
\text { around wing }\end{array}$ & $\begin{array}{l}\text { ending at wing } \\
\text { apex }\end{array}$ & $\begin{array}{l}\text { ending at wing } \\
\text { apex }\end{array}$ \\
\hline Gonocoxal apodeme & elongate & short & $\begin{array}{l}\text { moderate to } \\
\text { greatly elongate }\end{array}$ & short \\
\hline Aedeagus & $\begin{array}{l}\text { folded dor- } \\
\text { sally }\end{array}$ & straight & straight & $\begin{array}{l}\text { straight, or } \\
\text { folded ventrally }\end{array}$ \\
\hline $\begin{array}{l}\text { T2 sensory setae } \\
\text { patch shape }\end{array}$ & single & $\begin{array}{l}\text { single (or rarely } \\
\text { paired) }\end{array}$ & single & paired \\
\hline Wing vein $\mathbf{M}_{2}$ & present & present & present & absent \\
\hline Scutal macrosetae & absent & absent & present & absent \\
\hline Hypandrium & present & present & absent & absent \\
\hline
\end{tabular}

\section{Acknowledgements}

We thank Dr Ashley Kirk-Spriggs for loaning the material to Dr Mike Irwin, who then passed the material on to us for study. Thanks also to Drs Norman Woodley, Mike Irwin and Neal Evenhuis for their comments on the draft manuscript.

\section{References}

Bezzi, M. (1925) Quelques notes sur les bombyliides (dipt.) d'Egypte, avec description d'espèces nouvelles. Bulletin de la Société Entomologique d'Egypte, 8, 159-242.

Bowden, J. (1980) Family Bombyliidae. In R.W. Crosskey (Ed.), Catalogue of the Diptera of the Afrotropical Region. British Museum (Natural History), London, pp. 381-430.

Cole, F.R. (1923) A revision of the North American two-winged flies of the family Therevidae. Proceedings of the United States National Museum, 62, 1-140.

Dobson, J.R. (1999) Does Scenopinus fenestralis (Linnaeus) (Diptera, Scenopinidae) breed in beehives? Dipteristís Digest Second Series, 6, 42.

Evenhuis, N.L. (1991) Catalog of genus-group names of bee flies (Diptera: Bombyliidae). Bishop Museum Bulletin of Entomology, 5, 1-105.

Gnaspini, N,P. (1989) Comparative analysis of fauna associated with guano deposits of cavernicolous bats in Brazil, First Estimate. Revista Brasileira de Entomologia, 33, 183-192.

Hall, J.C. (1972) New North American Heterotropinae (Diptera: Bombyliidae). The Pan-Pacific Entomologist, 48, 37-50.

Hull, F.M. (1973) Bee flies of the world. The genera of the family Bombyliidae. Bulletin of the United States National Museum, 286, 1-687. 
Irwin M.E. \& Wiegmann B.M. (2001) A review of the southern African genus Tongamya (Diptera: Asiloidea: Mydidae: Megascelinae), with a molecular assessment of the phylogenetic placement of Tongamya and the Megascelinae. African Invertebrates, 43, 225-253.

Kelsey, L.P. (1969) A revision of the Scenopinidae (Diptera) of the world. Bulletin of the United States National Museum, 277, 1-336.

Kelsey, L.P. (1975) New Australian Scenopinidae (Diptera). Journal of the Australian Entomological Society, 14, 197-212.

Kelsey, L.P. (1981) Scenopinidae. In J.F. McAlpine et al. (eds), Manual of Nearctic Diptera 1: 525528. Vol. 1 Research Branch, Agriculture Canada. Monograph No. 27 Canadian Government Publishing Centre.

Melander, A.L. (1906) Some new or little-known genera of Empididae. Entomological News, 17, 370-379.

Melander, A.L. [1928] Diptera. Fam. Empididae. Fascicule No. 185. In P. Wytsman (ed.), Genera Insectorum, pp. 1-434. (1927) Brussels: L. Desmet-Verteneuil.

Melander, A.L. (1950) Taxonomic notes on some smaller Bombyliidae (Diptera). The Pan-Pacific Entomologist, 26, 139-156.

Metz, M.A., Winterton, S.L. \& Irwin, M.E. (2002) Notes on the functional morphology of terminalia from Prorates ballmeri Nagatomi \& Liu (Diptera: Scenopinidae: Proratinae) collected while in copula, with a description of the previously unknown female. Zootaxa, 76, 1-12.

Metz, M.A. (2003) Description of a new species of Caenotus Cole (Diptera: Scenopinidae) from Baja California Sur, Mexico, with a review of the genus. Zootaxa, 223, 1-11.

Nagatomi, A., Saigusa, T., Nagatomi, H. \& Lyneborg, L. (1991) Apsilocephalidae, a new family of the orthorrhaphous Brachycera (Insecta, Diptera). Zoological Science, 8, 579-591.

Nagatomi, A., Liu, N. \& Yanagida, K. (1994) Notes on the Proratinae Diptera: Scenopinidae). South Pacific Study, 14, 137-222.

Rahman, H.A.A., Shaumar, N.F., Soliman, Z.A. \& El Agoze, M.M. (1977 [1981]) Survey and taxonomy of parasites and predators of stored grain and grain products insects. Bulletin de la Société Entomologique d'Egypte, 61, 53-74.

Thompson, J.H., Knutson, L.V. \& Culp, O.S. (1970) Larva of Scenopinus sp. (Diptera Scenopinidae) causing human urogenital myiasis. Mayo Clinic Proceedings, 45, 597-601.

Winterton, S.L., Yang, L., Wiegmann, B.M. \& Yeates, D.K. (2001) Phylogenetic revision of Agapophytinae subf. n. (Diptera: Therevidae) based on molecular and morphological evidence. Systematic Entomology, 26, 173- 211.

Winterton, S.L., Skevington, J.H., Irwin, M.E. \& Yeates, D.K. (2000) Phylogenetic revision of Bonjeania Irwin \& Lyneborg (Diptera: Therevidae). Systematic Entomology, 25, 295-324.

Winterton, S.L., Irwin, M.E. \& Yeates, D.K. (1999a) Systematics of Nanexila gen. nov. (Diptera: Therevidae) from Australia. Invertebrate Taxonomy, 13, 237-308.

Winterton, S.L., Merritt D., OíToole, A., Irwin M.E. \& Yeates D.K. (1999b) Morphology and histology of the spermathecal sac, a novel structure in the female reproductive system of Therevidae (Diptera: Asiloidea). International Journal of Insect Morphology and Embryology, 28, 273-279.

Woodley, N.E. (1989) Phylogeny and classification of the "Orthorrhaphous" Brachycera. In J.F. McAlpine and D.M. Wood (eds), Manual of Nearctic Diptera 3. Hull: Research Branch Agriculture Monograph No. 32. Canadian Government Publishing Centre, pp. 1371-1395.

Yao, M.C. \& Lo K.C. (1992) Insect species and population densities in stored japonica rice in Taiwan. Chinese Journal of Entomology, 12, 161-169.

Yeates, D.K. (1992) Towards a monophyletic Bombyliidae (Diptera): the removal of the Proratinae (Diptera: Scenopinidae). American Museum Novitates, 3051, 1-30.

Yeates, D.K. (1994) The cladistics and classification of the Bombyliidae (Diptera: Asiloidea). Bulletin of the American Museum of Natural History, 219, 1-191. 
Yeates, D.K. (2002) Relationships of extant lower Brachycera (Diptera): A quantitative synthesis of morphological characters. Zoologica Scripta, 31, 105-121.

Yeates, D.K, Irwin, M.E. \& Wiegmann, B.M. (2003) Ocoidae, a new family of asiloid flies (Diptera: Brachycera: Asiloidea), based on Ocoa chilensis gen. and sp.n. from Chile, South America. Systematic Entomology, 28, 417-431.

Yucel, A, (1988) Investigation on determining flour beetles and their damages in meal factories and mills in southeastern Anatolia, Turkey. Bitki Koruma Bulteni, 28, 57-78.

Zaitzev, Z.F. (1972a) Some new species of bee flies (Diptera, Bombyliidae) from middle Asia and Kazakhstan. Zoologicheskii Zhurnal, 51, 455-58.

Zaitzev, Z.F. (1972b) On the fauna of bee flies (Diptera, Bombyliidae) of Mongolia, I. Insects of Mongolia, 1, 845-880. 